\title{
Ethnic differences in influences on quality of life at older ages: a quantitative analysis
}

\author{
MADHAVI BAJEKAL*, DAVID BLANE $\dagger$, INI GREWAL*, \\ SAFFRON KARLSEN** and JAMES NAZROO**
}

\begin{abstract}
This article sets out to examine ethnic differences in the key influences on quality of life for older people in the context of the increasing health and wealth of British older people generally and the ageing of the post-I945 migrants. It is based on secondary multivariate analysis of the Fourth National Survey of Ethnic Minorities of England and Wales. Respondents aged 45-74 years belonging to four ethnic groups (I,068 white, 5I4 Caribbean, 58I Indian and East African Asian, and I99 Pakistani) were included in the analysis, which focuses on differences between ethnic groups by age and gender, using the white population as the reference group. Four dimensions (incorporating seven factors) that influence the quality of life were determined among this age group: quality of neighbourhood (availability of local amenities, and problems with crime and the physical environment); social networks and community participation (strength of family networks, and community participation); material conditions (income, wealth and housing conditions) and health. The relative position of the four ethnic groups on the seven factors illustrated two contrasting patterns. For the factors based on conventional indicators of social inequalities - such as material circumstances, health, participation in formal social networks, and quality of the physical environment - the white group ranked highest, the Pakistanis lowest, and the Indian and Caribbean groups ranked second and third. But factors that capture more immediate and subjective elements, such as frequency of family contact and the desirability of the residential neighbourhood, displayed a diametrically opposite rank-order, with the Pakistani group ranked first and the white group fourth. The study highlights the value of examining separately the various influences on quality of life. Contradictory patterns are revealed in key influences that are hidden by global measures. The study also reveals the difficulty of identifying culturally-neutral measures of quality of locality, with ethnic minority groups having a more positive perception of their area than rated by conventional measures of area deprivation such as the Index of Deprivation.
\end{abstract}

$\boldsymbol{K E Y} \boldsymbol{W O R D S}$ - quality of life, ethnicity, older people, inequalities, area.

* National Centre for Social Research, London.

$\dagger$ Department of Primary Care and Social Medicine, Imperial College, London.

** Department of Epidemiology and Public Health, University College, London. 


\section{Introduction}

Profound changes are affecting life at older ages in Britain, although the extent to which they affect different ethnic groups has yet to be studied. Two traditions in British social gerontology have tended to differ in their relationship to these changes and in their emphasis on either poor or good quality of life at older ages. The idea of structured dependency describes the marginalisation from social and market relationships that follows statutory labour-market exit and the consequent forced economic dependence on deliberately low levels of pension (Townsend ig8i ; Walker I980). In contrast, the idea of the Third Age (Laslett I996) points to more recent developments; in particular, the increase in disability-free life expectancy (Bebbington I99I) and the spread of occupational pensions (Blundell and Johnson I998; Banks and Emerson 2000). As a result of these changes, a significant proportion of the population of industrialised countries can expect to spend many years after labour-market exit in reasonable health and comparative affluence. Whatever the conceptual status of these ideas (Bury 1995), they have the virtue of summarising real and conflicting tendencies in contemporary society. Theories of structured dependency and the Third Age can be reconciled by seeing them as ideal types, which are located at the extremes of a spectrum of quality of life at older ages. As the political-economy-of-ageing thesis has demonstrated (Walker I98I), an individual's location on this spectrum is likely to be influenced by their socio-demographic characteristics (ethnicity, gender, social class) and the effect of these on their past and present circumstances.

There is no doubt that since the Second World War, Britain's economy has benefited from the migrant labour that ethnic minority people have provided in public service and manufacturing. This generation of migrants is now moving into retirement and it has been suggested that older ethnic minority people face various multiple hazards (Blakemore and Boneham 1994; Ebrahim 1996), or double or triple jeopardy (Mays I983; Norman I985). There is, however, only very limited evidence on the circumstances of older ethnic minority people in Britain and evidence for younger people suggests a great diversity of experiences (Modood et al. 1997). These changes form the context of the present study of ethnic differences in quality of life at older ages.

The atheoretical nature of quality of life research has been noted often (Hornquist 1982; Gill and Feinstein 1994; Bowling 1997; Hunt 1997; Smith 2000). In the absence of a consensus about the theoretical basis of the concept of quality of life, a common approach has been to see it as the assemblage of a number of potentially relevant dimensions, such as health, 
finances, neighbourhood and social networks. Sophisticated versions of this approach, such as the 'Self-Evaluation Individual Quality of Life Direct Weighting' (SEIQoL-DW) measure allow the domains to be weighted according to the subjective importance that the individual attaches to each of them (Browne et al. 1996). This article takes a different approach, one which sees quality of life as a phenomenon that is distinct from its potential influences. Health, finances, neighbourhood, social networks and so forth are potential influences on quality of life, rather than its component factors. The present paper examines ethnic differences in these influences.

\section{Methods}

\section{Fourth National Survey of Ethnic Minorities}

The findings presented in this paper are based on secondary analysis of the Fourth National Survey of Ethnic Minorities (FNS). The FNS was a representative survey of ethnic minority and white people living in England and Wales conducted in 1993-94 by the Policy Studies Institute and Social and Community Planning Research (now the National Centre for Social Research). Respondents were allocated to an ethnic group on the basis of answers to a question on their family origins. The ethnic groups and numbers of respondents in the survey were: 1,205 Caribbean; 1,947 Indian and East African Asians; I,232 Pakistani; 598 Bangladeshi; 214 Chinese; and 2,867 white people. The overall response rate was 7 I per cent. The questionnaire covered a comprehensive range of information on both ethnicity and other aspects of the lives of the white and ethnic minority people, including demographic and socioeconomic factors. Further details of the methods and findings are reported elsewhere (Modood et al. I997; Nazroo 1997; Smith and Prior 1997).

The first, qualitative, phase of the study (of which the present paper is a part) included qualitative interviews with a follow-up sample of the FNS that featured four ethnically homogeneous groups as defined by family origin, religion and language (Grewal et al. 2004). These included people of Jamaican Caribbean origin, Gujarati Hindus of either Indian or East African origin, Punjabi Muslims from Pakistan; and white English. The four groups were selected to represent ethnic diversity in the meaning and experience of quality of life between groups, using groups that were as homogeneous as possible, to maximise the possibility of finding differences between them. The inclusion of the white group was seen as crucial, both to provide a point of comparison, and so that white ethnicity could be a focus of investigation. 
The analyses presented in this article built on the qualitative work. However, initial exploratory analysis of the FNS data suggested that a sample matched on tightly defined ethnic criteria, such as those used in the qualitative work, would be too small for robust quantitative analysis, particularly for the Punjabi Muslim and Gujarati Hindu groups (sample sizes I28 and II 7 respectively). To overcome the problem of small numbers, we included in this quantitative (second) phase of the study all those aged $45^{-74}$ years at the time of the FNS survey who identified themselves as being of white British ( $\mathrm{n}=\mathrm{I}, 068)$, Caribbean (514), Indian and East African Asian (58I), and Pakistani (I99) family origin. Respondents aged 45 and more years were included to cover those in early old age, particularly as previous research had shown that ethnic differences in life circumstances appear at younger ages (Nazroo 2004; Modood et al. 1997). Just over half of the Indian and Pakistani groups were aged under 55 years, compared to about two-in-five of the white British and Caribbean groups, and there were fewer women in the sample in the former $(45 \%)$ than in the latter (over $50 \%$ ) groups.

The FNS sampling procedures were designed to select probability samples of both households and individuals. In order to ensure that the sample was fully representative, areas were stratified on the basis of the concentration of ethnic minority people within them using information from the I99I population census. Because the number of primary sampling units (PSU), and the number of addresses selected within each PSU varied for each stratum, depending upon ethnic minority population density, sample weights were calculated to correct for unequal probabilities of selection (Smith and Prior 1997). For all analyses reported in this paper, the FNS data have been weighted by sample weights. The questionnaire coverage of the FNS survey allowed exploration of four dimensions or types of influence on quality of life that a literature review and the qualitative phase of the study suggested were important; namely, material factors, social participation and networks, health and neighbourhood environment. ${ }^{1}$ Questionnaire items related to each of the four dimensions were identified and included in the analysis.

\section{Factor scores}

To identify the constructs that underly each of the four dimensions, factor analysis was carried out using SPSS (Kim and Mueller I979). The key assumption underpinning factor analysis is that a set of questions (variables) all attempt to measure, albeit imperfectly, an underlying concept or attribute that cannot be measured directly. Factor analysis identifies the correlation among variables, groups together those that are related, and 
T A в L E I. Questionnaire items in each dimension and factor

\begin{tabular}{|c|c|c|}
\hline Dimensions and factors & Variables loading highly onto the factor ${ }^{1}$ & $\begin{array}{c}\text { Cronbach's } \\
\text { alpha }\end{array}$ \\
\hline \multicolumn{3}{|l|}{ Quality of neighbourhood } \\
\hline Amenities & $\begin{array}{l}\text { Problems with lack of: shops, schools, public } \\
\text { transport, leisure, places of worship, green } \\
\text { spaces, local industry }\end{array}$ & 0.47 \\
\hline Crime and environment & $\begin{array}{l}\text { Problems with: vandalism, car thefts, burglaries, } \\
\text { rubbish, nuisance teenagers, assaults, graffiti, } \\
\text { dog mess, safety on the streets, traffic, unkempt } \\
\text { gardens and paths, vacant properties }\end{array}$ & 0.79 \\
\hline \multicolumn{3}{|c|}{ Social networks and participation } \\
\hline Family networks & $\begin{array}{l}\text { Frequency of seeing, speaking, receiving letters } \\
\text { from parents or children in the last four weeks }\end{array}$ & 0.86 \\
\hline Community participation & $\begin{array}{l}\text { Being politically active, member of an } \\
\text { organisation, member of a trades union, } \\
\text { providing care for someone who does not live } \\
\text { with the respondent }\end{array}$ & 0.54 \\
\hline \multicolumn{3}{|l|}{ Material conditions } \\
\hline Income/wealth & $\begin{array}{l}\text { Equivalised income, existence of financial } \\
\text { concerns, receipt of means-tested benefits, } \\
\text { car ownership, number of consumer durables, } \\
\text { being in arrears with the rent or mortgage } \\
\text { (in last two years), availability of hot water or } \\
\text { heating in the house }\end{array}$ & 0.66 \\
\hline Housing conditions & $\begin{array}{l}\text { Availability of: a private bath and toilet, kitchen, } \\
\text { garden, hot water or heating in the house }\end{array}$ & 0.46 \\
\hline \multicolumn{3}{|l|}{ Health } \\
\hline & $\begin{array}{l}\text { Health limits ability to: walk more than one mile, } \\
\text { walk half a mile, climb one flight of stairs, lift or } \\
\text { carry groceries, participate in moderate } \\
\text { activities, bath or dress yourself. Long-standing } \\
\text { illness that limits work, poor self-assessed } \\
\text { health, registered disabled person, ever had } \\
\text { angina, high blood pressure, stroke or } \\
\text { experienced symptoms of respiratory illness }\end{array}$ & 0.86 \\
\hline
\end{tabular}

Note: I. Loadings weaker than $|0.20|$ not included.

produces a factor for each single underlying construct that the variables are measuring. For example, for the quality of neighbourhood dimension, including all the variables relating to perceptions of local area in the factor analysis yielded two factors. On inspection of the items with the largest loading or contribution to each factor score, the factors have been given descriptive titles (e.g. 'amenities' and 'crime and the physical environment') to indicate the underlying construct each is measuring, and for ease of reporting. We used the principal components method of factor extraction, with oblique rotation, setting the minimum eigenvalue to greater than one (Kim and Mueller I979). Table I shows the questionnaire items 
which loaded highly onto each of the seven factors, with Cronbach's alpha reliability coefficients to test the internal consistency between the items clustering under each factor. ${ }^{2}$

Not all respondents to the FNS were asked the same set of questions at interview. To maximise content coverage without increasing respondent burden, the FNS adopted a strategy of asking selected sections of the full questionnaire to random halves of the ethnic minority sample. In general, a core set of questions were asked of the white sample, and a largely nonoverlapping sub-set of these, plus additional questions eliciting further detail, was asked of the random halves of the ethnic minority sample. To derive comparable factor scores for respondents who had only been asked a sub-set of questions contributing to a factor, an approach combining factor and regression analysis was developed. This involved four steps. For the white sample, we first identified the seven factors and their constituent items. Two sets of multiple linear regression models for every factor score (dependent variable) were then run against the sub-set of items included in each half of the ethnic minority population as the dependent variables. The parameter estimates of these regression models were then applied to the corresponding sub-sets of the ethnic minority samples to calculate 'derived' factor scores for the ethnic minority sample members. These derived scores were validated against factor scores that would have been obtained from using just a sub-set of questions included in each half of the ethnic minority sample. Correlations between these and the derived factor scores were consistently high - typically around o.8-confirming the validity of the method. ${ }^{3}$

\section{Comparing factor scores between ethnic groups}

The distributions of factor scores between the four ethnic groups are presented in two ways - mean scores for each group and the percentage of the population with a score equal to or higher than the median for the white (reference) group. The first measure provides an absolute value and used analysis of variance to assess whether mean differences were significant at the 95 per cent confidence level. But, because factor scores are not an interval measure, distances between mean scores do not quantify the magnitude of differences between groups, rather they are indicative of relative position of each in relation to the population (normal) distribution. Our second measure - the proportion of each ethnic group with a score equal to or greater than the median value for the white population - therefore provides a readily interpretable measure of the relative distribution of factor scores between population groups. 
T A B L E 2. Summary statistics for factor scores by ethnic group ${ }^{1}$

\begin{tabular}{|c|c|c|c|c|c|}
\hline $\begin{array}{l}\text { Dimensions and } \\
\text { factor labels }\end{array}$ & Statistic & White & Caribbean & Indian & Pakistani \\
\hline \multicolumn{6}{|l|}{ Quality of neighbourhood } \\
\hline \multirow[t]{4}{*}{ Amenities } & Mean & -o.I9 & $0.3^{2}$ & 0.29 & 0.40 \\
\hline & Median & -0.10 & $0.5^{0}$ & 0.30 & 0.48 \\
\hline & Std deviation & 0.59 & 0.72 & 0.72 & 0.59 \\
\hline & Unweighted n & II 20 & 389 & $55^{6}$ & 276 \\
\hline \multirow[t]{4}{*}{ Crime/environment } & Mean & -0.05 & -0.06 & 0.18 & -0.38 \\
\hline & Median & 0.04 & 0.04 & $0.3 \mathrm{I}$ & -0.19 \\
\hline & Std deviation & $0.5^{8}$ & 0.79 & 0.70 & I.20 \\
\hline & Unweighted n & II 20 & 389 & $55^{6}$ & 276 \\
\hline \multicolumn{6}{|c|}{ Social networks and participation } \\
\hline \multirow[t]{4}{*}{ Family networks } & Mean & - o.I 6 & -0.15 & 0.00 & 0.13 \\
\hline & Median & -0.14 & O.OI & O.OI & O.OI \\
\hline & Std deviation & $0.8 \mathrm{I}$ & 0.57 & 0.73 & 0.77 \\
\hline & Unweighted n & I056 & $4 \mathrm{I} 7$ & 559 & 273 \\
\hline \multirow[t]{4}{*}{ Community participation } & Mean & 2.28 & I.I5 & I.I2 & 0.92 \\
\hline & Median & 2.09 & 2.09 & 2.09 & 2.09 \\
\hline & Std deviation & $0.6 \mathrm{I}$ & I.3I & I. 34 & I. 33 \\
\hline & Unweighted n & I056 & 417 & 559 & 273 \\
\hline \multicolumn{6}{|l|}{ Material conditions } \\
\hline \multirow[t]{4}{*}{ Income/wealth } & Mean & 0.00 & -0.67 & $-0.3^{2}$ & $-\mathrm{I} .42$ \\
\hline & Median & O.I5 & $-0.6 \mathrm{I}$ & -0.35 & $-\mathrm{I} \cdot 4^{8}$ \\
\hline & Std deviation & I.OO & I.OO & I.OO & I.OO \\
\hline & Unweighted n & 873 & $3^{2 I}$ & $35^{\mathrm{I}}$ & I89 \\
\hline \multirow[t]{4}{*}{ Housing conditions } & Mean & 0.00 & -0.18 & -0.03 & -0.44 \\
\hline & Median & 0.29 & $0.2 \mathrm{I}$ & 0.29 & O.I8 \\
\hline & Std deviation & I.OO & 0.90 & 0.94 & I. 55 \\
\hline & Unweighted n & 873 & $3^{2 \mathrm{I}}$ & $35^{\mathrm{I}}$ & I89 \\
\hline \multicolumn{6}{|l|}{ Health } \\
\hline \multirow[t]{4}{*}{ Health } & Mean & 0.00 & -0.23 & -0.15 & -0.45 \\
\hline & Median & 0.45 & 0.15 & 0.40 & 0.03 \\
\hline & Std deviation & I.OO & I.06 & I.05 & I.I7 \\
\hline & Unweighted n & IOI3 & $3^{8} 3$ & 533 & 259 \\
\hline \multicolumn{6}{|l|}{ Overall score } \\
\hline & Mean & 0.02 & $-2.3^{6}$ & $-\mathrm{I} \cdot 3^{\mathrm{O}}$ & -4.45 \\
\hline & Median & o.6I & $-\mathrm{I} .74$ & -0.94 & -4.18 \\
\hline & Std deviation & 3.78 & $4 \cdot 54$ & $4 \cdot 3^{6}$ & $4 \cdot 55$ \\
\hline & Unweighted $n^{2}$ & $8 \mathrm{I} 7$ & 259 & 3I9 & I66 \\
\hline
\end{tabular}

Notes: I. A higher score indicated a better outcome. 2. Overall scores were calculated only for cases with non-missing values for all seven factors.

For example, the mean health scores for the Pakistani and Indian group were -0.45 and -0.15 respectively (Table 2 ). This cannot be interpreted as saying that on average the Pakistani group is three times $(-0.45 /-0.15)$ less healthy than the Indian group. What it does indicate is that with a lower mean, the population distribution for the Pakistani group is shifted to the left (towards poorer health) of the distribution for the Indian group. The impact of this leftward shift in distribution is provided by our 
T A B L E 3. Percentages of the ethnic groups samples with scores greater or equal to the median factor score for white people

\begin{tabular}{llccc}
\hline \multirow{2}{*}{ Dimension } & \multicolumn{1}{c}{ Factor title } & \multicolumn{3}{c}{ Ethnic group $^{1}$} \\
\cline { 3 - 5 } & \multicolumn{1}{c}{ Caribbean } & Indian & Pakistani \\
\hline Quality of neighbourhood & Amenities & 72 & 69 & $8 \mathrm{I}$ \\
& Crime/environment & 53 & 64 & 45 \\
\multirow{2}{*}{ Social networks and } & Family networks & 67 & 73 & 79 \\
participation & Community participation & 54 & 55 & 53 \\
Material conditions & Income/wealth & 24 & 35 & 7 \\
\multirow{2}{*}{ Health } & Housing conditions & 33 & 50 & 25 \\
Overall score & Health & 29 & 32 & I9 \\
& & 28 & 33 & 9 \\
\hline
\end{tabular}

Note: I. Values higher than 50 per cent indicate positive outcomes on that factor relative to the white population.

second measure. Table 3 shows that just ig per cent of the Pakistani population had a (good) health score equal to or higher than the score for 50 per cent (median) of the white population. Expressed another way, 8I per cent of the Pakistani population had poorer underlying health, as measured by our health factor, relative to $5^{\circ}$ per cent of the white group; or 3I per cent more Pakistani people (i.e. 8I minus $5^{0}$ per cent) rated their health state lower than the median health state for the white group. In contrast, the table shows that i 8 per cent more (or $68 \%$ in total) Indian people rated their health state as lower than the median health state for the white group.

While Tables 3 and 4 show the mean score and population distribution by ethnicity overall, Tables 5 and 6 show the corresponding measures subdivided by ethnicity, age group and gender. These sets of tables allowed a comparative assessment using two types of measures (mean versus population) across two kinds of distributions: overall by ethnic group and by age group and gender within each group. However, sub-group analysis is limited by small numbers in each cell and values based on an (unweighted) count of less than 30 cases have been placed in brackets to indicate that estimates may be unreliable.

A summary overall measure, or total score, was derived by summing together the scores for all factors after they had been standardised ( $z$ scores) to the distribution for the white reference group. As dimensions other than health were represented by two factors each, we weighted the health factor score by two and the rest were unweighted (i.e. weighted by one). This total score should not be considered as a 'quality of life' score, rather 
T A B L E 4. Mean factor scores, by gender, ethnic group and age group

\begin{tabular}{|c|c|c|c|c|c|c|c|c|c|c|}
\hline \multirow[b]{2}{*}{ Dimension } & \multirow[b]{2}{*}{ Factor title } & \multirow{2}{*}{$\begin{array}{c}\text { Age } \\
\text { (years) }\end{array}$} & \multicolumn{4}{|c|}{ Men } & \multicolumn{4}{|c|}{ Women } \\
\hline & & & White & Caribbean & Indian & Pakistani & White & Caribbean & Indian & Pakistani \\
\hline \multirow{6}{*}{$\begin{array}{l}\text { Quality of } \\
\text { neighbourhood }\end{array}$} & \multirow[t]{3}{*}{ Amenities } & $45^{-54}$ & -0.18 & 0.29 & 0.26 & $0.3^{2}$ & -0.20 & 0.39 & 0.23 & 0.46 \\
\hline & & $55^{-64}$ & -0.20 & 0.25 & 0.37 & $0.3^{8}$ & -0.19 & 0.37 & 0.39 & $0.5^{\mathrm{I}}$ \\
\hline & & $65-74$ & -0.19 & 0.36 & O.I9 & 0.26 & -0.18 & 0.17 & 0.26 & {$[0.26]$} \\
\hline & \multirow[t]{3}{*}{ Crime/environment } & $45^{-54}$ & -0.03 & -0.04 & o.I9 & -0.28 & 0.06 & -0.02 & 0.20 & -0.16 \\
\hline & & $55^{-64}$ & -0.06 & $-\mathrm{O} . \mathrm{II}$ & 0.22 & -0.80 & -0.15 & 0.03 & o.19 & -0.46 \\
\hline & & $65-74$ & -0.06 & $-\mathrm{O} . \mathrm{OI}$ & 0.04 & -0.34 & -0.08 & $-0.3^{8}$ & 0.07 & -0.03 \\
\hline \multirow{6}{*}{$\begin{array}{l}\text { Social networks } \\
\text { and participation }\end{array}$} & \multirow[t]{3}{*}{ Family networks } & $45^{-54}$ & $-\mathrm{O} . \mathrm{OI}$ & 0.02 & 0.33 & 0.22 & 0.02 & -0.10 & -0.02 & 0.07 \\
\hline & & $55^{-64}$ & -0.24 & -0.16 & -0.12 & 0.28 & -0.22 & -0.20 & -0.27 & O.OI \\
\hline & & $65-74$ & $-0.3^{8}$ & -0.40 & -0.25 & 0.00 & -0.25 & -0.16 & $-\mathrm{O} . \mathrm{II}$ & {$[-0.3 \mathrm{I}]$} \\
\hline & \multirow{3}{*}{$\begin{array}{l}\text { Community } \\
\text { participation }\end{array}$} & $45^{-54}$ & 2.20 & I.59 & I. 43 & I.06 & 2.33 & I.O7 & 0.93 & 0.93 \\
\hline & & $55^{-64}$ & $2.3^{6}$ & 0.89 & I.07 & 0.72 & 2.28 & I. I5 & I.04 & 0.75 \\
\hline & & $65-74$ & 2.25 & 0.89 & $0.9^{2}$ & $\mathrm{I} .2 \mathrm{I}$ & 2.25 & I. 65 & $0.9 \mathrm{I}$ & {$[0.93]$} \\
\hline \multirow{6}{*}{$\begin{array}{l}\text { Material } \\
\text { conditions }\end{array}$} & \multirow[t]{3}{*}{ Income/wealth } & $45^{-54}$ & 0.24 & -0.30 & -0.16 & $-\mathrm{I} .25$ & 0.29 & -0.49 & -0.07 & - I.47 \\
\hline & & $55^{-64}$ & $-\mathrm{O} . \mathrm{OI}$ & -0.93 & -0.49 & $-\mathrm{I} .44$ & -0.06 & -0.67 & -0.49 & {$[-\mathrm{I} \cdot 39]$} \\
\hline & & $65-74$ & $-\mathrm{O.II}$ & -0.77 & {$[-0.83]$} & {$[-\mathrm{I} .76]$} & -0.49 & $-\mathrm{I} \cdot 33$ & {$[-0.67]$} & {$[-\mathrm{I} .83]$} \\
\hline & \multirow[t]{3}{*}{ Housing conditions } & $45^{-54}$ & 0.09 & -0.06 & $-\mathrm{O} . \mathrm{OI}$ & -0.20 & 0.17 & 0.02 & 0.04 & $-0.5^{0}$ \\
\hline & & $55^{-64}$ & 0.03 & $-0.3^{2}$ & $-0.1 \mathrm{I}$ & $-0.7 \mathrm{I}$ & -0.06 & $-0.2 \mathrm{I}$ & 0.03 & {$\left[-0.5^{8}\right]$} \\
\hline & & $65-74$ & -0.15 & $-0.5^{8}$ & {$[\mathrm{O} . \mathrm{I} 4]$} & {$[-0.18]$} & -0.15 & $-\mathrm{O} . \mathrm{OI}$ & {$\left[-0.5^{\mathrm{I}}\right]$} & {$[-0.77]$} \\
\hline \multirow[t]{3}{*}{ Health } & \multirow[t]{3}{*}{ Health } & $45^{-54}$ & $0.3^{2}$ & $0.3^{8}$ & 0.17 & $-\mathrm{O} . \mathrm{I} 5$ & O.I3 & -0.26 & O.OI & -0.37 \\
\hline & & $55^{-64}$ & 0.15 & -0.39 & -0.34 & $-0.5^{8}$ & -0.10 & -0.46 & -0.40 & $-0.5^{0}$ \\
\hline & & $65-74$ & -0.28 & -0.22 & -0.43 & $-\mathrm{I} .35$ & -0.37 & $-0.5^{8}$ & $-0.7 \mathrm{I}$ & {$[-0.19]$} \\
\hline \multirow[t]{3}{*}{ Overall score } & & $45^{-54}$ & I.I7 & 0.34 & 0.57 & $-2.7 \mathrm{I}$ & I.I4 & $-\mathrm{I} .97$ & $-\mathrm{I} \cdot 32$ & -4.27 \\
\hline & & $55^{-64}$ & $0.5^{0}$ & -3.92 & -2.73 & -6.19 & -0.55 & -2.54 & $-\mathrm{I} .72$ & {$[-5 \cdot 13]$} \\
\hline & & $65-74$ & - I.IO & -4.07 & {$\left[-3 \cdot 3^{8}\right]$} & {$[-6.2 \mathrm{I}]$} & $-\mathrm{I} .77$ & {$[-3.26]$} & {$[-3.66]$} & {$[-5.66]$} \\
\hline
\end{tabular}

Note: Means based on less than 30 counts are in brackets []. 
T A B L E 5. Percentages of the ethnic groups by gender and age group with factor scores greater or equal to the median for the white gender-age group

\begin{tabular}{|c|c|c|c|c|c|c|c|}
\hline \multirow[b]{2}{*}{ Factor title } & \multirow{2}{*}{$\begin{array}{l}\text { Ages } \\
\text { (years) }\end{array}$} & \multicolumn{3}{|c|}{ Men } & \multicolumn{3}{|c|}{ Women } \\
\hline & & Caribbean & Indian & Pakistani & Caribbean & Indian & Pakistani \\
\hline \multirow[t]{3}{*}{ Amenities } & $45^{-54}$ & 73 & 68 & 75 & 68 & 60 & 78 \\
\hline & $55^{-64}$ & 70 & 80 & 72 & 79 & 77 & $9 \mathrm{I}$ \\
\hline & $65-74$ & 84 & 69 & 88 & 67 & 60 & [86] \\
\hline \multirow[t]{3}{*}{ Crime/environm't } & $45^{-54}$ & 60 & 67 & $5^{2}$ & 43 & 62 & $5^{\mathrm{I}}$ \\
\hline & $55^{-64}$ & $3^{8}$ & $5^{8}$ & 27 & 65 & $7 \mathrm{I}$ & 47 \\
\hline & $65-74$ & 57 & 62 & $4^{\mathrm{I}}$ & 35 & 54 & [4I] \\
\hline \multirow[t]{3}{*}{ Family networks } & $45^{-54}$ & 74 & 78 & 77 & 24 & 23 & I8 \\
\hline & $55^{-64}$ & 63 & 78 & 8I & 70 & $6 \mathrm{I}$ & 75 \\
\hline & $65-74$ & 54 & 69 & 83 & 68 & 75 & [75] \\
\hline \multirow{3}{*}{$\begin{array}{l}\text { Community } \\
\text { participation }\end{array}$} & $45^{-54}$ & I9 & I6 & 9 & I5 & 5 & I \\
\hline & $55^{-64}$ & II & 7 & I & 53 & 54 & $4^{8}$ \\
\hline & $65-74$ & 45 & $5^{\mathrm{I}}$ & 65 & 77 & 53 & [56] \\
\hline \multirow[t]{3}{*}{ Income/wealth } & $45^{-54}$ & I8 & 26 & 4 & I7 & 35 & 6 \\
\hline & $55^{-64}$ & 13 & 25 & 3 & $2 \mathrm{I}$ & 27 & [Io] \\
\hline & $65-74$ & 20 & [Io] & {$[0]$} & 4 & [36] & {$[6]$} \\
\hline \multirow[t]{3}{*}{ Housing condit'ns } & $45^{-54}$ & 23 & $3^{6}$ & 24 & 28 & $3^{8}$ & 24 \\
\hline & $55^{-64}$ & 28 & 44 & I8 & $3^{2}$ & 47 & [33] \\
\hline & 65-74 & 24 & [68] & {$[24\rfloor$} & 33 & [39] & {$[0]$} \\
\hline \multirow[t]{3}{*}{ Health } & $45^{-54}$ & 47 & 34 & 24 & 28 & $3^{\mathrm{I}}$ & I8 \\
\hline & $55^{-64}$ & 20 & 26 & 17 & $3^{2}$ & $3^{8}$ & $2 \mathrm{I}$ \\
\hline & $65-74$ & 44 & 34 & 26 & 33 & $4^{0}$ & [20] \\
\hline \multirow[t]{3}{*}{ Overall score } & $45^{-54}$ & 26 & 49 & I6 & 25 & 28 & 2 \\
\hline & $55^{-64}$ & 24 & 27 & II & 44 & $3^{2}$ & [14] \\
\hline & $65-74$ & $3^{\mathrm{I}}$ & [33] & [I4] & [36] & [22] & [26] \\
\hline
\end{tabular}

Note: Percentages based on less than 30 counts are in brackets [].

as an empirically derived summary of the joint influence of the four measured dimensions.

Neighbourhood scores compared with ward level Index of Deprivation, 2000

The perception of the local neighbourhood as reported by the FNS respondents was compared with national estimates of relative deprivation for the same areas, as measured by the Index of Deprivation 2000 (ID200o) (Department of the Environment, Transport and the Regions (DETR) 200o). Linking the postcode of the respondent's address to their ward of residence, the mean composite ID2000 score and the score of one of its constituent domain, geographical access to services (e.g. shops, GP, school) were derived for the same wards and compared. The ID20oo did not have a separate domain relating to crime or the physical environment. 
T A в L E 6. Perceived access to local amenities by FNS sample compared with Index of Deprivation scores

\begin{tabular}{|c|c|c|c|c|}
\hline \multirow[b]{2}{*}{ Statistic and amenity measure } & \multicolumn{4}{|c|}{ Ethnic group } \\
\hline & White & Caribbean & Indian & Pakistani \\
\hline \multicolumn{5}{|l|}{ Means } \\
\hline Local amenities, perceived (higher, better) & -0.19 & $0.3^{2}$ & 0.29 & 0.40 \\
\hline ID 2000 access to amenities (higher, better) $^{1}$ & -0.63 & -0.97 & -0.74 & -0.97 \\
\hline ID20oo overall score (lower, more affluent) ${ }^{\mathbf{1}}$ & $2 \mathrm{I} .8$ & $39 \cdot 7$ & 30.8 & $5^{\mathrm{O} . \mathrm{I}}$ \\
\hline \multicolumn{5}{|l|}{$\operatorname{Ranks}(\mathrm{I}=$ best $)$} \\
\hline Local amenities, perceived & 4 & 2 & 3 & I \\
\hline ID2000 access to amenities ${ }^{1}$ & I & $3=$ & 2 & $3=$ \\
\hline ID20oo overall score ${ }^{1}$ & I & 3 & 2 & 4 \\
\hline
\end{tabular}

Note: I. Index of Deprivation 2000. See text and DETR (2000).

\section{Results}

\section{Quality of neighbourhood}

The overall mean factor score for the availability of local amenities was significantly higher for all three ethnic minority groups relative to the white group (Table 2). The population proportions with a score equal to or higher than the white group median score confirm that proportionately more ethnic minority people had scores higher than the median score for the white population (Table 3). For instance, 8I per cent of people of Pakistani origin had a score equal to or higher than the median $(50 \%)$ score for the white group. Overall, the population proportions above the white median cut-point were highest for Pakistani people, and successively lower for Caribbean, Indian and white groups. This overall rank position by ethnicity was consistently observed across successive age bands and for each gender (Tables 4 and 5). There was no significant difference in factor scores with increasing age or between men and women, indicating that the perception of the availability of local amenities did not alter with advancing age or by gender for any of the four groups.

Crime and the quality of the physical environment (e.g. vandalism) were perceived to be significantly more of a problem by the Pakistani group and less of a problem by the Indian group, relative to the white group (Tables 2 and 3). With advancing age, Pakistani men and women continued to be likely to report problems with crime and the quality of the physical environment relative to the white groups of the same age and gender (Table 5).

\section{Comparison of perceived versus objective indices of quality of neighbourhood}

The perception of the local neighbourhood as reported by the FNS respondents was in sharp contrast to 'formal' national estimates of relative 
deprivation for the same areas, as measured by the ID20oo (Table 6) (DETR 2000). The comparison shows that residents' perception of the quality of the local neighbourhood is inversely related to both the ID200o composite score and its constituent service access score. At one end of the spectrum, Pakistani residents living in wards classified as the most deprived, and with the poorest access to services relative to all the other groups, rated their neighbourhoods highly on the amenities factor. At the other end, the white group, living in relatively more affluent areas, perceived the quality of local amenities in their neighbourhoods to be a lot worse than any of the ethnic minority groups. This disparity between objective and perceptual indicators of neighbourhood amenities was observed for all four groups, resulting in an inverse ranking between the groups for these two measures.

\section{Social networks and participation}

Contact with family (family networks factor) was significantly higher in Indian and Pakistani groups compared with the white group. Looking at the percentage of people scoring the same as or higher than the median score for the white sample, the Pakistani group ranked first $(79 \%)$, followed by the Indian (73\%), Caribbean $(67 \%)$ and the white $(50 \%)$ groups (Table 3$)$. The same pattern was observed for men across all age groups, and for women aged 55 and more years. Women in the youngest age band (45-54 years) in all three ethnic minority groups, however, had markedly lower levels of familial contact relative to women in the white group (Tables 4 and 5). These differences were not statistically significant because of small numbers. In general, contact with family in all four groups declined significantly with the addition of each Io years of age from 45 years (Table 4 ).

Overall levels of community participation were significantly higher for the white group, but did not vary much between the ethnic minority groups. For all groups, the distribution was highly skewed, with most informants to the survey reporting no active participation on either the formal (e.g. political parties, trades union) or informal (e.g. voluntary work, informal care) types of civic engagement. As a result, the median score and the corresponding percentage distributions above the white group's median score were very similar across ethnic minority groups. There was considerably greater variation by age and gender. Overall, participation among women was significantly lower than for men (Table 4). After retirement age (65-74 years), Caribbean women and Pakistani men had higher numbers participating in community activities than other groups (Table 5). Before retirement, men in all the ethnic minority 
groups had markedly lower levels of social participation than white men. The same held for women aged 45-54 years, but their participation increased to levels similar to those of white women aged $55^{-64}$ years.

\section{Material conditions}

Of all of the seven factors, the gap between the white and the ethnic minority group was largest for that of income and wealth. A familiar pattern emerged in the ordering of the groups: economic resources were highest for the white group, followed by the Indian, Caribbean and the Pakistani groups; and each ethnic group had significantly lower resources than the group preceding it (Tables 2 and 3). Scores also declined significantly with age, and women had lower scores overall for all four groups (Table 4). In terms of the relative population distribution, 93 per cent of the Pakistani group, 76 per cent of the Caribbean group and 65 per cent of the Indian group had an income score of less than the median for the white group. There was no marked difference in the overall relative position on income by age group or gender, except for the sharp fall in relative income for older Caribbean and white women (Table 5).

Housing conditions factor scores were lower for all of the ethnic minority groups relative to the white group, but were significantly different only for the Caribbean and Pakistani groups (Table 2). Housing conditions deteriorated significantly with increasing age across all groups, but there was no significant difference by gender (Table 4). The relative population distributions of the Indian group was similar to those of the white group, but housing conditions for only one-third of people of Caribbean origin and one-quarter of Pakistani people were on a par with the median experience for the white and Indian groups (Table 3 ).

\section{Health}

The pattern of differences in the health factor is clear, with significant differences between groups by ethnicity, age and gender. As we would expect, health declined with advancing age for all groups and, overall, men had better scores than women (Table 4). All ethnic minority groups had significantly lower health scores compared with the white group and, among the three minority groups, Caribbean and Indian groups had similar levels of health and Pakistani people had significantly poorer health (Table 2). Overall, fewer than 20 per cent of people of ethnic minority origin in this age group enjoyed the average (median) level of health of the reference white group. 
T A в L E 7. Factor ranks based on mean scores by ethnic group

\begin{tabular}{lcccc}
\hline Factors & White & Caribbean & Indian & Pakistani \\
\hline Amenities & 4 & 2 & 3 & I \\
Crime/environment & 2 & 3 & I & 4 \\
Family networks & 4 & 3 & 2 & I \\
Community participation & I & 2 & 3 & 4 \\
Income/wealth & I & 3 & 2 & 4 \\
Housing conditions & I & 3 & 2 & 4 \\
Health & I & 3 & 2 & 4 \\
Overall score & I & 3 & 2 & 4 \\
\hline
\end{tabular}

Note: Highest rank is I.

\section{Ranking and overall score}

The ranks of the four groups on the seven factors illustrate two contrasting patterns (Table 7). The ranks for the factors of health, material conditions, participation in community networks, and crime and the physical environment revealed a consistent pattern, with the Pakistani group lowest, the Caribbean third, and the Indian and white groups second and first respectively for all except crime and physical environment, for which the Indian group ranked first. On the other hand, the factors measuring frequency of family contact and availability of local amenities displayed a diametrically opposite rank-order, with the Pakistani group ranked first and the white fourth.

The overall score reflects the ranks based on the first group of factors rather than the second. This was expected (it is constructed as a simple aggregation of the scores on all dimensions), and therefore manifests the pattern observed for the majority of factors. The overall scores declined significantly with advancing age, and on average women had significantly lower scores than men (Table 4). After controlling for age and gender, the differences between the groups remained statistically significant. The cumulative effect of aggregating the factor scores on the relative population distribution is stark: less than one-tenth $(9 \%)$ of the Pakistani group had a composite score at least as high as the median for the white group, with one-third of the Indian (33\%) and under one-third of the Caribbean $(28 \%)$ group at the same level (Table 3$)$.

\section{Discussion}

This analysis has shown that there are significant differences between ethnic groups in the key influences on the quality of life of older people. Groups ranked by conventional indicators of social inequalities - such as 
material circumstances, health, civic engagement through membership of community networks, and the quality of the physical environment - show the normally assumed pattern of relative disadvantage, with the white group ranked highest, Pakistani lowest, and the Indian and Caribbean groups ranked second and third. But factors such as the desirability of the residential neighbourhood and the strength of family networks, which capture more immediate and subjective influences and potentially have as great an impact on quality of life, reveal the opposite rank-order, with the Pakistani group ranked first and the white group last. While there is considerable supporting evidence for our findings in respect of the former set of factors (e.g. health and income), the latter two have received less attention and are discussed below. Because this is an exploratory investigation of aspects of ethnicity that have previously been ignored, the discussion is necessarily speculative.

\section{Social networks and community participation:}

A comparison of the rank orders on the family networks factor used here and those of a broadly similar measure in the social capital module of the General Household Survey in 2000 (GHS200o) reveals some contradictory findings. The GHS20oo showed that the percentage of adults aged i 6 and more years who spoke to their relatives daily was highest for the people describing themselves as Pakistani/Bangladeshi (36\%), followed by Indian $(35 \%)$, Black (30\%) and white (27\%) groups (Coulthard et al. 2002). Despite the inclusion of a younger cohort in the GHS20oo, the rank order of groups based on the frequency of family contact is consistent with the FNS findings. However, the GHS20oo 'satisfactory relatives network' score - a combination of frequency of contact and proximity of residence of close relatives - was found not to be significantly different between all ethnic minority groups (combined) and the white group. At the time of the I99I Census, nearly all ethnic minority people aged 45 and more years had been born outside the United Kingdom (Coulthard et al. 2002). Hence, older ethnic minority people are mainly primary immigrants and so less likely than the indigenous population to have as wide a network of close relatives (e.g. siblings and parents) living in the country. It is therefore possible that including residential proximity in the 'satisfactory relatives network' score has attenuated ethnic differences in the frequency of family contacts observed in the GHS2Ooo.

Community participation, on the other hand, was significantly lower for all ethnic minority groups relative to the white group. The GHS20oo, which includes a wider range of measures of civic engagement than the FNS, similarly reported significantly lower levels of participation for ethnic 
minority people aged i 6 and more years once other socio-demographic factors were taken into account (Coulthard et al. 2002). It is possible that much of the mainstream forms of civic participation - such as through trades unions, political parties and charities - may be less accessible to ethnic minority groups (e.g. because of differences in employment patterns and histories), and/or immigrant communities may direct more of their energies towards their own families or ethnic communities (e.g. through informal caring and religious activities). The findings from the qualitative phase of this study indicate that for Pakistani men and Caribbean women over the retirement age, the major focus of their community engagement was respectively through the mosque and church (Grewal et al. 2004). It is possible that forms of community activity that are channelled through religion are regarded by ethnic minority groups as integral to their faith and would not, therefore, prompt a positive response to a survey question that asks about 'voluntary participation in an organisation'.

The pattern of ethnic minority groups' social engagement - through the family and religious organisations - may indicate a dynamic interaction between the effect of migration and cultural values, beliefs and social structures. The centrality of the family in the ethos of rural communities, characteristic of the origins of many South Asian and Caribbean immigrants, may be reinforced by moving into a hostile environment and expressed through an increased emphasis upon maintaining family contacts and preserving cultural identity (Grewal et al. 2004).

\section{Perception of neighbourhood}

Ethnic minority groups had on average a more positive perception of the availability of amenities and services in the local area than the white group, despite the low ratings they gave their localities on aspects such as safety, vandalism and the quality of the physical environment. Overall indices of area deprivation, such as the ID2000, also rate the localities where the ethnic groups lived as on average more deprived than the areas where the white groups lived. The GHS2ooo findings indicate that, for the general population, problems with the availability of facilities are highly correlated with low perceptions of personal security and the quality of the neighbourhood.

The difference between objective assessments and subjective perceptions of residential neighbourhood by ethnic minority groups may be explained in one of two ways: lower expectations of the external world, or conversely, higher levels of satisfaction because of greater investment in the locality to facilitate the continuation of the 'old' ways of life (Grewal et al. 2004). Analysis of I991 census data for electoral wards showed 
that the Pakistani group had the highest residential concentrations, followed by the Caribbean and the Indian groups (Peach I996). Although generally located in deprived inner-city areas, residential concentration imparts tangible benefits for ethnic minority communities; e.g. bringing together community resources to build places of worship and to sustain shops and businesses that serve community-specific needs (Grewal et al. 2004). Interestingly the levels of residential segregation mirrored the levels of satisfaction with local amenities: the Pakistani group scored highest on both, followed by the Caribbean and Indian groups. Instruments designed to measure area deprivation and disadvantage based on administrative and census data, such as the ID2000, attach little or no weight to such factors, which may be central to the lives of migrant populations.

\section{Health and economic position}

Our findings on health and economic position reflect those of other studies (Cooper et al. 200o). For example, analysis of the FNS and the ig99 Health Survey for England (HSE99) suggest that ethnic inequalities in health increase markedly with age, with small differences in early childhood disappearing by late childhood and early adulthood, but reappearing in early-middle age and growing through later adulthood: the differences are very marked by early old age (Nazroo 2004). Analysis of the HSE99 also revealed widespread exclusion from paid work and poverty in some ethnic groups. Among men aged 50-65 years, rates of employment for all ethnic minority groups were lower than for the white English group, with particularly low rates for Pakistani (3I \%) and Bangladeshi (i6\%) men (Nazroo 2004). Brodie (I996) suggested that differences in pre-retirement employment opportunities structure the risk of poverty for ethnic minority people in old age. In terms of income, more than go per cent of Bangladeshi people aged 50 or more years, and more than three-quarters of Pakistani people aged $5^{0}$ or more years were in the lowest income tertile, with just over one-third of white English people in this age group (Nazroo 2004). While such economic inequalities are present throughout the lifecourse, they too appear to widen at older ages. Ethnic minority people may have been less likely to have worked for employers who offered occupational pensions and to have themselves contributed to state pension schemes or privately-purchased pensions: such pensions investments are easiest for those in permanent and well-paid jobs. Older women from some ethnic minority groups were especially disadvantaged in this respect, for they were highly likely to have been in low-paid work or never to have been employed. 


\section{Overall index of indicators of quality of life in older people}

In addition to the systematic differences between ethnic groups that have been noted, the overall scores declined significantly with advancing age, and women had significantly lower scores than men. A progressive decline in health status with advancing age is inevitable and must contribute to the stepped fall in the overall scores. However, the scale of the decline in the overall scores indicates that a depletion of economic resources had also made a significant contribution to the worsening of their overall circumstances in old age.

\section{Limitations of the study}

The findings presented here have been based on a secondary analysis of the FNS, but the survey variables did not allow direct assessments of inequalities in quality of life, nor of some of the dimensions of influence on quality of life that our qualitative work has shown to be important (Grewal et al. 2004), nor either of lifecourse measures that are known to have an indirect effect on the quality of life (Blane et al. 2004). It is not possible to trace causal chains from a cross-sectional quantitative survey, but only the cumulative effects of past lifecourse trajectories on factors that are known to influence the quality of life. Some of the variables had a limited range of response categories, which is particularly problematic for factor analysis. The consequences were seen in the relatively low explained variances and Cronbach's alpha reliability coefficients for the key (or highly loading) variables. Although the eigenvalues provided reassurance about the validity of our findings, the data limitations imply a need for caution when interpreting the findings, especially given the small sample sizes for subgroup analyses.

The study has shown that unless a wide range of the dimensions of experience that influence the quality of life are examined, its estimation is liable to miss key characteristics of the lives of older ethnic minority people. How these various indicators impact on the individual's experience of the quality of life and the value placed on each may also vary systematically between groups as indicated by our qualitative work (Grewal et al. 2004).

\section{Acknowledgements}

We would like to thank the UK Economic and Social Research Council which funded the study (Grant L480254020), the older people who generously gave their time to take part in the Fourth National Survey and its follow-up interviews. We 
thank Dr Susan Purdon (Director, Survey Methods Unit, National Centre for Social Research) for statistical advice, particularly in developing methods to address the problem of missing data, and express our appreciation of the anonymous reviewers' helpful comments.

\section{NOTES}

I The qualitative phase of this study identified six factors that influenced the quality of life for older people across ethnic groups: having a role, support networks, income and wealth, health, having time, and independence (Grewal et al. 2004).

2 Low coefficients of Cronbach's alpha indicate that the items do not belong to the same conceptual domain. There is no agreement over the minimum acceptable standard. Some regard 0.5 as indicating good internal consistency (DeVellis 2003).

3 Details of the method and the validation of derived scores are available on request as a pdf file from the corresponding author.

\section{References}

Banks, J. and Emmerson, C. 2000. Public and private pension spending: principles, practice and the need for reform. Fiscal Studies, 21, I-63.

Bebbington, A. I99I. The expectation of life without disability. Population Trends, 66, 26-9.

Blakemore, K. and Boneham, M. 1994. Age, Race and Ethnicity: A Comparative Approach. Open University Press, Buckingham.

Blane, D., Higgs, P., Hyde, M. and Wiggins, R. 2004. Life course influences on quality of life in early old age. Social Science and Medicine, 58, 2171-9.

Blundell, R. and Johnson, P. I998. Pensions and labour market participation in the UK. American Economic Reviewe, 88, I68-72.

Bowling, A. 1997. Measuring Health: A Review of Quality of Life Measurement Scales. Second edition, Open University Press, Buckingham.

Brodie, J. 1996. Perspectives on Poverty and Ethnic Minority Elders. Age Concern England, London.

Browne, J., O'Boyle, C., McGee, H., McDonald, J. and Joyce, C. I996. Development of a direct weighting procedure for quality of life domains. Quality of Life Research, 6, 30I-9.

Bury, M. 1995. Ageing, gender and sociological theory. In Arber, S. and Ginn, J. (eds), Connecting Gender and Ageing: A Sociological Approach. Open University Press, Buckingham, $73-87$.

Cooper, H., Arber, S., Daly, T., Smaje, C. and Ginn, M. 200o. Ethnicity, Health and Health Behaviour: A Study of Older Age Groups. Summary report, Health Development Agency, London.

Coulthard, M., Walker, A. and Morgan, A. 2002. People's Perception of Their Neighbourhood and Community Involvement: Results from the Social Capital Module of the General Household Survey 200o. Stationery Office, London.

Department of the Environment, Transport and the Regions (DETR) 200o. Index of Deprivation, 200o. Regeneration Research Summary 3I, DETR, London.

DeVellis, R. F. 2003. Scale Development: Theory and Applications. Second edition, Sage, Thousand Oaks, California.

Ebrahim, S. I996. Ethnic elders. British Medical Fournal, 31 3, 6ro-3.

Gill, T. and Feinstein, A. I994. A critical appraisal of the quality of quality of life measurements. Fournal of the American Medical Association, 272, 619-26. 
Grewal, I., Nazroo, J., Bajekal, M., Blane, D. and Lewis, J. 2004. Influences on quality of life: a qualitative investigation of ethnic differences among older people in England. Fournal of Ethnic and Migration Studies, 3o, 4 , in press.

Hornquist, J. I982. The concept of quality of life. Scandinavian Fournal of Social Medicine, ro, $57-6$ I.

Hunt, S. 1997. The problem of quality of life. Quality Life Research, 6, 205-I2.

Kim, J. O. and Mueller, C. W. I979. Factor Analysis: Statistical Methods and Practical Issues. Sage, London.

Laslett, P. 1996. A Fresh Map of Life. Second edition, Macmillan, London.

Mays, N. 1983. Elderly south Asians in Britain: a survey of the relevant literature and themes for future research. Ageing \& Society, 3, 7I-97.

Modood, T., Berthoud, R., Lakey, J., Nazroo, J., Smith, P., Virdee, S. and Beishon, S. 1997. Ethnic Minorities in Britain: Diversity and Disadvantage. Policy Studies Institute, London.

Nazroo, J. Y.rg97. The Health of Britain's Ethnic Minorities: Findings from a National Survey. Policy Studies Institute, London.

Nazroo, J. 2004. Ethnic disparities in aging health: what can we learn from the United Kingdom? In Anderson, N., Bulatao, R. and Cohen, B. (eds), Critical Perspectives on Racial and Ethnic Differentials in Health in Late Life. National Academy Press, Washington DC, $677-702$.

Norman, A. I985. Triple Feopardy: Growing Old in a Second Homeland. Centre for Policy on Ageing, London.

Peach, C. (ed.) I996. Ethnicity in the I99I Census, volume 2. Her Majesty's Stationery Office, London.

Smith, A. 2000. Quality of life: a review. Education and Ageing, I5, 419-35.

Smith, P. and Prior, G. I997. The Fourth National Survey of Ethnic Minorities: Technical Report. Social and Community Planning Research, London.

Townsend, P. I98I. The structured dependency of the elderly. Ageing \& Society, I, 5-18.

Walker, A. I980. The social creation of poverty and dependency in old age. Fournal of Social Policy, 9, I, 49-75.

Walker, A. г981. Towards a political economy of old age. Ageing E Society, I, 73-94.

Address for correspondence:

Accepted I2 May 2004

Madhavi Bajekal, National Centre for Social Research, 35 Northampton Square, London EGIV oAX

e-mail:m.bajekal@natcen.ac.uk 